\title{
Activation of the transcription factor NF-kB by retrieval is required for long-term memory reconsolidation
}

\author{
Emiliano Merlo, Ramiro Freudenthal, Héctor Maldonado, and Arturo Romano ${ }^{1}$ \\ Laboratorio de Neurobiología de la Memoria, Departamento de Fisiología, Biología Molecular y Celular, Facultad de Ciencias \\ Exactas y Naturales, Universidad de Buenos Aires, IFIByNE, CONICET, Ciudad Universitaria, Pab. II, 2do piso (1428EHA), \\ Buenos Aires, Argentina
}

\begin{abstract}
Several studies support that stored memories undergo a new period of consolidation after retrieval. It is not known whether this process, termed reconsolidation, requires the same transcriptional mechanisms involved in consolidation. Increasing evidence supports the participation of the transcription factor NF- $\mathrm{KB}$ in memory. This was initially demonstrated in the crab Chasmagnathus model of associative contextual memory, in which re-exposure to the training context induces a well characterized reconsolidation process. Here we studied the role of NF- $\mathrm{B}$ in reconsolidation. $\mathrm{NF}-\kappa \mathrm{B}$ was specifically activated in trained animals re-exposed to the training context but not to a different context. NF- $\mathrm{B}$ was not activated when animals were re-exposed to the context after a weak training protocol insufficient to induce long-term memory. A specific inhibitor of the NF-кB pathway, sulfasalazine, impaired reconsolidation when administered 20 min before re-exposure to the training context but was not effective when a different context was used. These findings indicate for the first time that NF- $\kappa$ B is activated specifically by retrieval and that this activation is required for memory reconsolidation, supporting the view that this molecular mechanism is required in both consolidation and reconsolidation.
\end{abstract}

Several studies suggest that memory retrieval induces a period of lability before the re-storage of the memory trace (Misanin et al. 1968; Mactutus et al. 1979; Nader et al. 2000; Sara 2000; Pedreira et al. 2002). Whether such a memory phase, termed reconsolidation, is mechanistically similar to the initial consolidation is a matter of debate (Debiec et al. 2002; Myers and Davis 2002; Lee et al. 2004; Salinska et al. 2004). Little is known about the molecular pathways involved in this process. Several questions exist: Does the reconsolidation process involve molecular mechanisms similar to those of consolidation? Is transcription factor (TF) activation during retrieval a general phenomenon, present in different memory models from diverse taxa? Is this activation functionally associated with the reconsolidation mechanism?

A growing amount of experimental data links nuclear factor $\kappa \mathrm{B}$ (NF-кB) with animal behavior, long-term memory (LTM) formation, and synaptic plasticity. This TF has recently received special interest because it can play a dual role, acting as a signaling molecule after its activation at the synapse, and as a transcription initiator upon reaching the nucleus. In response to specific stimuli, Rel/NF- $\kappa \mathrm{B}$ translocates to the nucleus as a consequence of the proteolytic degradation of its inhibitor, the inhibitor $\kappa \mathrm{B}(\mathrm{I} \kappa \mathrm{B})$ protein, when phosphorylated by a specific kinase, named ІкB kinase (IKK) (DiDonato et al. 1997; Mercurio et al. 1997). Experimental data support the participation of NF-кB in long-term potentiation (Meberg et al. 1996; Albensi and Mattson 2000; Freudenthal et al. 2004). The first evidence indicating that learning activates NF-кB was found in the context-signal learning of the crab Chasmagnathus. In this model, a high correlation between memory formation and NF- $\kappa \mathrm{B}$ activation was demonstrated (Freudenthal et al. 1998; Freudenthal and Romano

\footnotetext{
1'Corresponding author.

E-mail aromano@fbmc.fcen.uba.ar; fax 54-11-4576-3447.

Article and publication are at http://www.learnmem.org/cgi/doi/10.1101/ Im.82705.
}

2000). In addition, the inhibition of this TF by a specific IKK inhibitor, sulfasalazine, induced amnesia during the two periods in which NF-кB was active (Merlo et al. 2002). Moreover, activated NF-кB was found in synaptic terminals after LTM induction, giving physiological support for the synapse-to-nucleus signaling role of NF- $\kappa B$ (Freudenthal and Romano 2000). More recently, evidence of a role of NF- $\mathrm{B}$ in memory in rodents was obtained (Yeh et al. 2002, 2004; Meffert et al. 2003).

In the Chasmagnathus paradigm, the repeated presentation of a visual danger stimulus (an opaque figure passing overhead) provokes the fading of the initial escape response (Lozada et al. 1990) that is actively replaced by a freezing response. Fifteen or more spaced presentations of the figure induce an association between the iterated stimulus (unconditioned stimulus, US) and contextual features (conditioned stimulus, CS). A long-term memory is formed, termed context-signal memory (CSM), which lasts for at least a week and entails protein and mRNA synthesis (Pedreira et al. 1995, 1996). A brief re-exposure to the training context without US presentation induces reconsolidation (Pedreira et al. 2002), while longer exposure of $1 \mathrm{~h}$ or more switches to extinction, both requiring de novo protein synthesis (Pedreira and Maldonado 2003).

Here we explored the NF-кB activation during memory reactivation by a brief re-exposure to the training context. We tested whether this TF is required for reconsolidation, in keeping with the view that basic molecular mechanisms of consolidation are necessary to restore reactivated memory.

\section{Results}

NF- $\mathrm{K} B$ is activated by context re-exposure

In the first experiment, we evaluated nuclear NF-кB activity in the central brain after 5 min of context re-exposure, using an electrophoretic mobility shift assay (EMSA) with central brain nuclear extracts. This technique is appropriate to measure DNA 
binding activity and nuclear translocation of NF- $\mathrm{B}$ and, therefore, to estimate the TF activation. In the crab central nervous system, only one retarded band is detected with this assay. This band corresponds to a protein complex that specifically binds to the $\kappa \mathrm{B}$ consensus sequence, as was previously demonstrated by competition assays (Freudenthal et al. 1998; Freudenthal and Romano 2000).

During the training session (diagram in Fig. 1A) a group of animals (training group, TR) received 15 spaced trials, while a control group (CT) remained in the experimental device (actom-

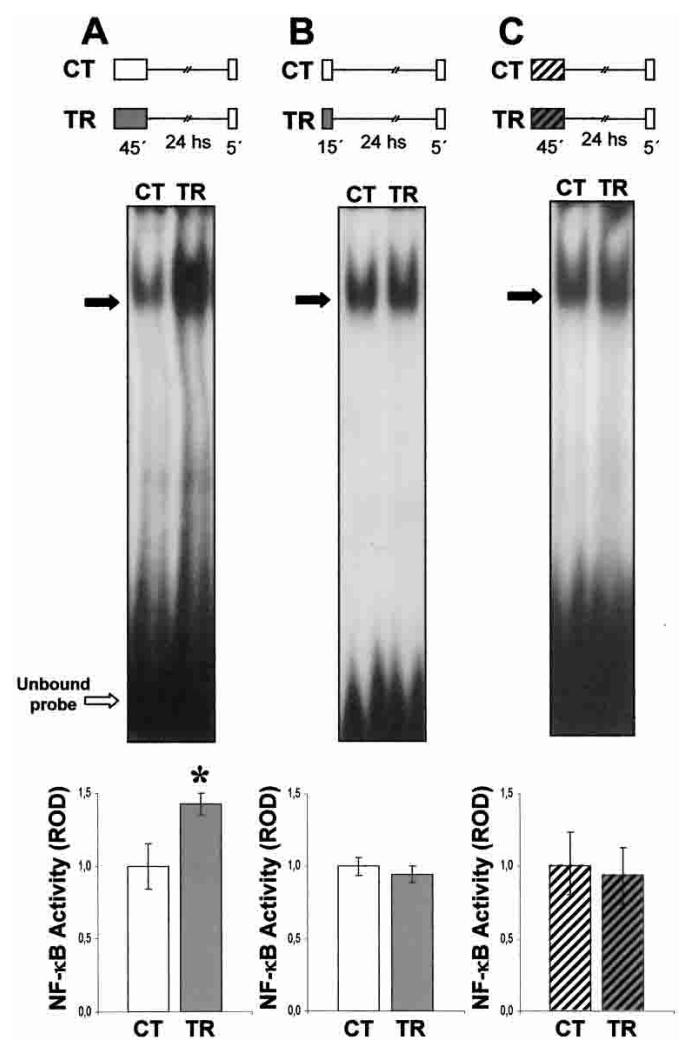

Figure 1. NF- $\kappa B$ activity after exposure session. (A) NF- $\kappa B$ activation after re-exposure to the training context. $\kappa B$ binding activity measured immediately after re-exposure to the training context by EMSA. Top: Experimental design. Two groups of animals were used. On Day 1, the TR group was trained with 15 spaced trials, (a protocol that induces CSM consolidation), and the CT group was located in the actometers but remained untrained; $24 \mathrm{~h}$ later, both groups were re-exposed to the training context (container with plain walls) for 5 min, anesthetized, and then nuclear extracts from central brain were obtained. Middle: Representative EMSA performed with nuclear extracts obtained from CT and TR groups. The specific bands are indicated by filled arrows. Bottom: $N F-\kappa B$ activity relative to $C T$. Mean \pm SEM of relative optic density (ROD) values of the specific NF- $\mathrm{B}$ retarded band normalized to CT group media, obtained in four independent experiments. ${ }^{*}, P<0.05, t$-test. $(B)$ NF-кB is not activated by context re-exposure after a weak training protocol. Top: Experimental design. The same as in $A$, but animals were trained with six instead of 15 spaced trials. Middle: As in A. Bottom: NF-кB activity relative to $C T$. Mean $\pm S E M$ of ROD values of the specific NF- $\kappa B$ retarded band normalized to $C T$ group media, obtained in five independent experiments. (C) NF- $\kappa$ B activity after exposure to a novel context. $\kappa B$ binding activity immediately after exposure to a different context than that of training. Top: Experimental design. A pair of CT-TR groups was exposed to the container with white-and-black striped walls; $24 \mathrm{~h}$ later, both groups were exposed to the novel context (normal container) for 5 min, anesthetized, and then nuclear extracts from central brain were obtained. Middle: As in A. Bottom: NF- $\kappa$ B activity relative to CT. Mean \pm SEM of ROD values of the specific NF- $\kappa B$ retarded band normalized to CT group media, obtained in four independent experiments. eter) for the same time (45 $\mathrm{min})(n=20$ for each group). Twentyfour hours later, animals were lodged in the respective actometers for $5 \mathrm{~min}$ and then sacrificed. Nuclear extracts obtained from the central brain were incubated with labeled DNA oligonucleotide containing $\kappa \mathrm{B}$ consensus sequence. A representative EMSA is shown in Figure 1A. A higher level of specific NF- $\kappa B$ complex is observed in the TR group compared to the CT group. Densitometric analysis of four independent experiments showed a significant increment of $40 \%$ in NF- $\mathrm{B}$ activity in the TR group $(P<0.05$, $t$-test) (histogram in Fig. $1 \mathrm{~A})$. In previous work, we found NF- $\mathrm{\kappa B}$ activation during consolidation ranging from $50 \%$ to $200 \%$, depending on the training protocol employed (Freudenthal and Romano 2000; Merlo et al. 2002). In addition, previous results indicate that the level of NF-кB activity $24 \mathrm{~h}$ after training was equal to that of the control group for animals not re-exposed to the context (Freudenthal and Romano 2000). Thus, a brief re-exposure to the training context induced NF-кB activation in trained animals.

\section{NF- $\kappa B$ is not activated by context re-exposure after a weak training}

In the second experiment, a weak training protocol of six trials was used during the training session. This protocol is not enough to induce CSM or to activate NF-кB (Freudenthal and Romano 2000). During the training session (diagram in Fig. 1B), a group of animals (TR) received six spaced trials while a CT group remained in the actometer for the same time $(15 \mathrm{~min})(n=20$ for each group). Twenty-four hours later, animals were lodged in the respective actometers for $5 \mathrm{~min}$ and then sacrificed. A representative EMSA is presented in Figure 1B. Similar levels of NF-кB activity were found for both groups. A densitometric analysis of five independent experiments showed no significant differences between the CT and TR groups (histogram in Fig. 1B). Thus, the NF-кB activity level remains invariant when re-exposure takes place after a weak training protocol that does not induce CSM.

\section{NF- $\kappa$ B activation is specific to the training context}

To evaluate whether this activation is specific to the contextual clues present during learning, we performed the following experiment, introducing visual changes in the context between training and re-exposure. On the first day, both trained and control animals were exposed to actometers with black and white striped walls. On the second day, crabs were exposed for 5 min to the normal nonstriped actometers (diagram in Fig. 1C). Using this environmental shift, previous studies demonstrated that crabs do not show CSM when contextual cues are changed between training and testing, indicating that this memory is specific to the training context (Tomsic et al. 1998; Hermitte et al. 1999). Immediately after context exposure, animals were sacrificed and EMSAs were performed as indicated previously. Figure $1 \mathrm{C}$ shows a representative experiment, in which the level of NF$\kappa \mathrm{B}$ activity was similar in both groups. No significant differences were found in four independent experiments (histogram, Fig. 1C), indicating that NF-кB activation occurred only when the animals were re-exposed to the same context previously used for training.

\section{NF- $\mathrm{B}$ inhibition impairs reconsolidation}

To test whether the observed NF- $\mathrm{B}$ activation is functionally related to memory reconsolidation, we used the drug sulfasalazine, which inhibits NF-кB by specific inhibition of IKK (Wahl et al. 1998; Weber et al. 2000). Systemic administration of a $6 \mu \mathrm{g} / \mathrm{g}$ dose $(50 \mu \mathrm{L}$ of $5 \mathrm{mM})$ of this drug was previously used to inhibit basal and training-induced NF-кB activity in Chasmagnathus central brain. Maximal sulfasalazine inhibition of basal NF-кB activ- 
A
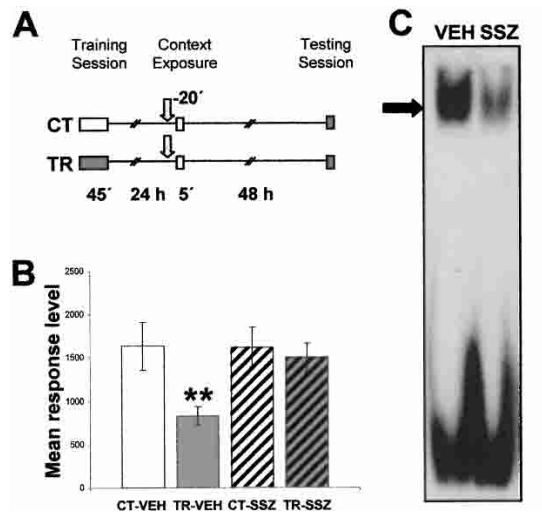

Figure 2. $(A, B)$ Effect of sulfasalazine injection before context reexposure. (A) Experimental design: On Day 1 the animals were trained with 15 trials (TR groups) or were located in the actometers but remained untrained (CT groups). On Day 2, a pair of CT-TR groups was injected with $6 \mu \mathrm{g} / \mathrm{g}$ sulfasalazine, and the other with vehicle solution (indicated with arrows); 20 min later, all groups were re-exposed to the training context for $5 \mathrm{~min}$. Forty-eight hours after the exposure session, the groups were tested for memory retention with one trial in the training context. (B) Performance at testing session. $(C, D)$ Effect of sulfasalazine injection on NF- $\mathrm{KB}$ activity. $\kappa \mathrm{B}$ binding activity measured 20 min after vehicle (VEH) or $5 \mathrm{mM}$ sulfasalazine (SSZ) injection by EMSA. In each experiment, two groups of animals were used ( $n=13$ per group). (C) Representative EMSA performed with nuclear extracts obtained from VEH or SSZ groups. The specific band is indicated with an arrow. (D) NF-kB activity relative to $V E H$. Mean \pm SEM of relative optic density (ROD) values of the specific NF- $\mathrm{kB}$ retarded band normalized to VEH group media, obtained in four independent experiments. ${ }^{*}, P<0.05$, $t$-test.

ity was achieved 30 to $45 \mathrm{~min}$ after injection (Merlo et al. 2002). The behavioral effects of sulfasalazine were analyzed in previous work. Doses of sulfasalazine ranging from 1 to $25 \mathrm{mM}$ revealed no deleterious effects on spontaneous behavior. In relation to memory formation, we tested two doses of sulfasalazine, 1 and 5 $\mathrm{mM}$. Only the $5 \mathrm{mM}$ solution effectively impaired CSM when administered immediately pretraining or $5 \mathrm{~h}$ after training, but not when injected immediately or $24 \mathrm{~h}$ after training, in accord with the periods during consolidation in which NF- $\mathrm{kB}$ is in the process of activation (Merlo et al. 2002). Furthermore, considering a potential effect of sulfasalazine on cyclooxygenase (COX), the effect of a drug that inhibits prostaglandin but not NF-кB pathway (Yin et al. 1998) in memory consolidation was evaluated. This drug, indomethacin, did not show an amnestic effect on CSM, and the disruption of memory formation found with sulfasalazine was attributed to IKK inhibition (Merlo et al. 2002).

In the next experiment, we trained two groups of animals and established two untrained control groups (Fig. 2A). Twentyfour hours after training, one CT-TR pair was injected with vehicle (CT-VEH and TR-VEH groups), and the other pair was injected with $6 \mu \mathrm{g} / \mathrm{g}$ sulfasalazine (CT-SSZ and TR-SSZ groups). Twenty min after injection, crabs were re-exposed to the training context for $5 \mathrm{~min}$. Forty-eight hours later; all groups were tested with one trial of figure presentation. As expected, a significant difference was found between the CT-VEH and TR-VEH groups $\left(F_{(1,134)}=12.21 ; P<0.01\right)$, with a low level of response for the TR-VEH groups, indicating retention of the CSM (Fig. 2B). However, no differences were found between the CT-SSZ and TR-SSZ groups, demonstrating that sulfasalazine induced amnesia when injected shortly before re-exposure. No differences were found between CT groups, indicating that the drug did not provoke unspecific effects on crab response. Considering that sulfasalazine effect on NF- $\mathrm{B}$ was not previously evaluated $20 \mathrm{~min}$ after injection, the following experiment was designed to test this issue. Groups of 13 animals were injected either with vehicle (VEH) or with $5 \mathrm{mM}$ sulfasalazine (SSZ) solution and 20 min later were sacrificed to obtain nuclear extracts from central brain. Four independent repetitions of this experiment were performed and analyzed by EMSA. Figure 2C shows a representative EMSA in which a clear inhibition of NF- $\mathrm{kB}$ activity in the SSZ group is observed. The comparison between densitometric values of VEH and SSZ groups did show significant differences $(P<0.05, t$-test $)$ (Fig. 2D).

In order to rule out a nonspecific effect of sulfasalazine, in the following experiment we tested whether post-reactivation short-term memory remains intact. A pair of CT-TR groups was administered $6 \mu \mathrm{g} / \mathrm{g}$ sulfasalazine (CT-SSZ and TR-SSZ) and another pair with vehicle (CT-VEH and TR-VEH), 20 min before re-exposure. Four hours later, a testing session was performed (Fig. 3A). Figure 3B illustrates the results. Both CT-TR groups' comparisons showed significant differences [CT-VEH vs. TRVEH, $F\left({ }_{(1,156)}\right)=7.17, P<0.01$; CT-SSZ vs. TR-SSZ, $F\left({ }_{(1,156)}\right)=6.5$, $P<0.05]$, indicating that sulfasalazine had no amnesic effect in post-reactivation short-term memory. As expected, no differences were found between CT groups.

Considering that sulfasalazine injection was ineffective when administered $24 \mathrm{~h}$ after training without re-exposure to the actometers (Fig. 3C,D; data from Merlo et al. 2002), these results strongly suggest that inhibition of NF-кB disrupts the stabilization of the reactivated CSM. Should such an interpretation be correct, sulfasalazine is not expected to induce amnesia if the contextual clues are changed between training and re-exposure. To test this possibility, in the next experiment a pair of CT-TR groups was administered sulfasalazine and reexposed to the same context used in their training session (CT-SA and TR-SA groups). Another CT-TR pair of groups injected with sulfasalazine was exposed to a novel context (striped actometers) (CT-NO and TRNO groups). Both pairs of groups were tested $48 \mathrm{~h}$ after reexposure (Fig. 4A). No differences were found between CT-SA and
A

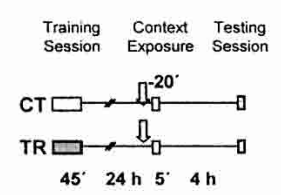

B

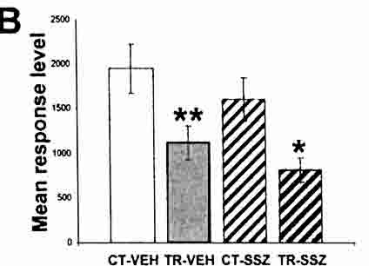

C

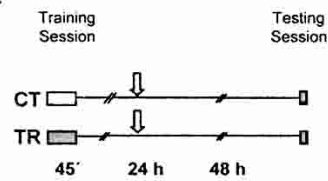

$D_{-}$

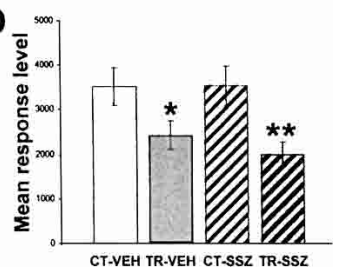

Figure 3. $(A, B)$ Effect of sulfasalazine injection in short-term reactivated memory. $(A)$ Experimental design. On Day 1, the animals were trained with 15 trials (TR groups) or were located in the actometers but remained untrained (CT groups). On Day 2, a pair of CT-TR groups was injected with $6 \mu \mathrm{g} / \mathrm{g}$ sulfasalazine, and the other with vehicle solution (indicated with arrows). Twenty minutes later, all groups were re-exposed to the training context for $5 \mathrm{~min}$. Four hours after the exposure session, the groups were tested for memory retention with one trial in the training context. (B) Performance at testing session. $(C, D)$ Effect of sulfasalazine injection without context re-exposure on long-term reactivated memory. (C) Experimental design. On Day 1 the animals were trained with 15 trials (TR groups) or were located in the actometers but remained untrained (CT groups). On Day 2, a pair of CT-TR groups was injected with $6 \mu \mathrm{g} / \mathrm{g}$ sulfasalazine or with vehicle solution (indicated with arrows); $48 \mathrm{~h}$ after the injections, the groups were tested for memory retention with one trial in the training context. (D) Animals' performance at the testing session (data redrawn from Merlo et al. 2002). Values are mean response level \pm SEM at testing. ${ }^{*}, P<0.05 ;{ }^{* *}, P<0.01$. 


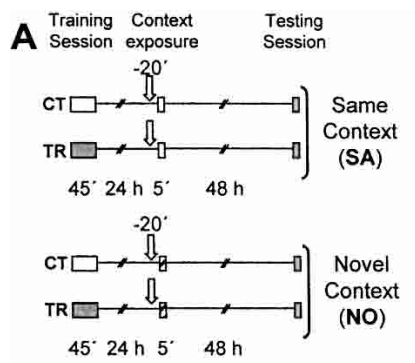

B

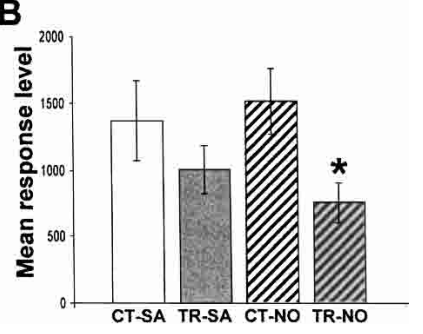

Figure 4. Effect of sulfasalazine injection during exposure to a novel context. ( $A$ ) Experimental design. On Day 1 the animals were trained with 15 trials (TR groups) or were located in the actometers but remained untrained (CT groups). On Day 2 all groups were injected with $6 \mu \mathrm{g} / \mathrm{g}$ sulfasalazine (indicated by arrows), and 20 min later a CT-TR pair was exposed to the training context (container with plain walls) and the other pair to a novel context (container with white-and-black striped walls). Forty-eight hours after the exposure session, the groups were tested for memory retention with one trial in the training context. (B) Performance at the testing session. Values are mean response level \pm SEM at testing. *, $P<0.05$.

TR-SA groups, indicating that sulfasalazine induced amnesia (Fig. 4B). However, the TR-NO group showed a significantly lower response with respect to CT-NO $\left(F_{(1,78)}=5.89 ; P<0.05\right)$, indicating that the drug did not induce amnesia when animals were exposed to a context different from that of training. After context shift, CSM is not expected to be evoked and, consequently, the results of both experiments indicate that sulfasalazine is only effective during memory reactivation.

Considering a supposed effect of sulfasalazine on COX, the following experiment was aimed at testing whether the pretraining administration of the COX inhibitor indomethacin impairs long-term memory when administered shortly before reexposure. Two pairs of CT-TR groups were used. Twenty-four hours after training, one CT-TR pair was injected with vehicle (CT-VEH and TR-VEH groups), and the other pair was injected with $50 \mu \mathrm{l}$ of $100 \mu \mathrm{M}$ indomethacin (CT-IND and TR-IND groups). This dose was the highest employed in previous studies that did not induce deleterious effects on spontaneous behavior. Twenty minutes after injection, crabs were re-exposed to the training context for $5 \mathrm{~min}$. Forty-eight hours later, all groups were tested with one trial of figure presentation (Fig. 5A). A significant difference was found between the CT-VEH and TR-VEH groups $\left(F_{(1,111)}=4.34 ; P<0.05\right)$ and between the CT-IND and TR-IND groups $\left(F_{(1,111)}=8.45 ; P<0.01\right)$, indicating that indomethacin did not show effects on memory retention and thus did not affect reconsolidation (Fig. 5B).

Hence, the results in this section support that NF-кB activation during retrieval is required for memory reconsolidation.

\section{Discussion}

Two lines of independent evidence presented in this work support the participation of NF- $\mathrm{kB}$ in memory reconsolidation. First, re-exposure to the training context induced NF- $\kappa$ B activation in trained animals but not in untrained controls. Furthermore, such activation was not observed when a change in a visual trait rel- evant for CSM retrieval was introduced, or when re-exposure to the training context was presented after a weak training protocol (insufficient to induce CSM or to activate NF-кB). These results indicate that NF- $\mathrm{BB}$ is activated in the nucleus only when memory is retrieved during the remainder presentation. Second, sulfasalazine- a specific inhibitor of the NF- $\mathrm{kB}$ activating kinase IKK-impaired CSM when it was administered during reexposure, but was not effective when animals were exposed to the visual-shifted context. Additionally, sulfasalazine did not affect short-term reactivated memory when administered before re-exposure. This fact supports the view that the amnestic effect of this drug is specific to the mechanisms that underlie long-term memory reconsolidation.

Sulfasalazine action was initially attributed to COX inhibition, but the effect on prostaglandin levels was controversial and, in general, sulfasalazine and its metabolite 5-aminosalicilic acid (5-ASA) seem to be weak or very weak inhibitors of COX (Hoult 1986). Wahl et al. (1998) found that sulfasalazine, but not its metabolites, is a potent and specific inhibitor of NF-кB. More recently, the same group reported direct inhibition of IKK $\alpha$ and IKK $\beta$ due to interference of the drug with the ATP binding site (Weber et al. 2000). Here we found that the administration of the COX inhibitor indomethacin does not affect reconsolidation. On the basis of this result, the amnestic effect of sulfasalazine found in our work is attributed only to IKK inhibition.

The results presented here thus indicate that NF-кB activation induced by retrieval is a necessary step in memory reconsolidation. Together with a recent study in which the inhibition of CREB by genetic manipulation impeded reconsolidation (Kida et al. 2002), our results suggest that TF activation is required for stabilization of reactivated memory. Moreover, the activation of TFs in reconsolidation seems to be an evolutionarily conserved feature from crustacea to mammals. Interestingly, other reports suggest that consolidation and reconsolidation involve different mechanisms. Following memory reactivation, neurotransmitter antagonists and metabolic inhibitors have shown effective doses and time windows different from those observed for initial consolidation. In some cases, the effect in reconsolidation was only transient and/or required different neuronal substrates (Summers et al. 1997; Przybyslawski et al. 1999; Bahar et al. 2004; Salinska et al. 2004). The inhibition in hippocampus of the TF C/EBP in

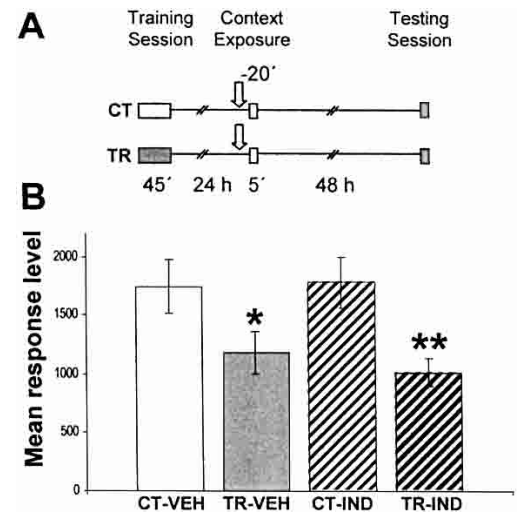

Figure 5. Effect of indomethacin injection during context re-exposure. (A) Experimental design: On Day 1 the animals were trained with 15 trials (TR groups) or were located in the actometers but remained untrained (CT groups). On Day 2, a pair of CT-TR groups was injected with $50 \mu \mathrm{L}$ of a $500 \mu \mathrm{M}$ solution of indomethacin or with vehicle solution (indicated with arrows). Twenty minutes later, all groups were re-exposed to the training context for $5 \mathrm{~min}$, and $48 \mathrm{~h}$ after the exposure session the groups were tested for memory retention with one trial in the training context. (B) Performance at the testing session. Values are mean response level \pm SEM at testing. ${ }^{*}, P<0.05 ;{ }^{* *}, P<0.01$. 
passive avoidance in rat impairs memory consolidation but not reconsolidation (Taubenfeld et al. 2001). This result together with other pharmacological studies suggests that the hippocampus is not involved in reconsolidation in this task. Another TF, zif268, was found to be necessary for reconsolidation but not for consolidation, whereas other pathways activated by brainderived neurotrophic factor (BDNF) seem to be required in consolidation but not in reconsolidation (Lee et al. 2004). Altogether, these data hint at the idea that consolidation and reconsolidation require different kinetics for the same pathways or the action of different signaling pathways. However, some TFs, such as NF-кB and CREB, seem to be necessary in both processes and could be key participants subserving the basic mechanisms that underlie consolidation and reconsolidation. As Dudai and Eisenberg (2004) concluded in a recent review, the available data suggest that consolidation and reconsolidation share many mechanistic components, yet reconsolidation is not a faithful recapitulation of consolidation.

Results obtained in the first two experiments of the present study suggest that NF- $\mathrm{B}$ is rapidly activated in the nucleus by retrieval. Five minutes of context re-exposure was enough to induce a $40 \%$ increase regarding control activity. During training, more than 10 trials (more than 30 min of training) were necessary to observe a significant increase in NF- $\kappa \mathrm{B}$ activity (Freudenthal and Romano 2000). The very fast NF-кB activation after reexposure to the context suggests that molecular pathways that lead to its nuclear translocation and DNA binding activity are facilitated by training. This facilitation persists for at least one day, allowing a rapid NF- $\mathrm{B}$ response when specific signals are present.

In a recent study, Pedreira and Maldonado (2003) found that re-exposure duration determines CSM course towards either reconsolidation or extinction, depending on the reminder duration. When the animals were re-exposed for $5 \mathrm{~min}$, cycloheximide impaired memory. In contrast, after an exposure of $1 \mathrm{~h}$ or longer, cycloheximide preserved CSM, impeding extinction. When the crab is exposed to the original training context, the learned context-signal association is recalled and the danger stimulus (US) is expected. The non-occurrence of the predicted stimulus is only corroborated when the animal is removed from the actometer, leading to either reconsolidation or extinction. Thus, cellular and molecular mechanisms that subserve reconsolidation and extinction are expected to initiate after removal from the context. In the present study, however, animals were sacrificed immediately after removal, indicating that NF-кB is rapidly activated by retrieval and not by removal. Why should the TFs involved in neural plasticity be activated before the temporal point when either reconsolidation or extinction is triggered? According to recent hypotheses on synaptic specificity, two steps are required for neuronal plasticity. Initially, a synapseto-nucleus signaling mechanism for macromolecule synthesis is induced by neuronal activity and, after that, a capture mechanism takes place, directing these macromolecules to the activated synapses, a process that defines the circuits to be reinforced. In models of neural plasticity, a time window is opened after neuronal stimulation during which the synthesized macromolecules can be captured in specific synapse populations (Frey and Morris 1997; Martin et al. 1997). A similar process may be induced by retrieval. In the present study, the products of NF-кB-dependent gene expression could be directed to specific synapses after removal, once reconsolidation or extinction has been determined.

$\mathrm{NF}-\kappa \mathrm{B}$ is a tightly controlled pathway for responding to complex combinations of stimuli like those involved in learning. The participation of NF- $\mathrm{kB}$ in both consolidation and reconsolidation stresses the important role of this TF in the regulation of gene expression specifically required for memory storage.

\section{Materials and Methods}

\section{Animals}

Adult male Chasmagnathus granulatus intertidal crabs, $2.6-2.9 \mathrm{~cm}$ across the carapace, weighing $17 \pm 0.2 \mathrm{~g}(n=60)$, were collected from water less than $1 \mathrm{~m}$ deep in the estuarine coasts of San Clemente del Tuyú, Argentina, and transported to the laboratory, where they were lodged in plastic tanks $(30 \times 45 \times 20 \mathrm{~cm})$ filled to $0.5 \mathrm{~cm}$ depth with diluted (12\%o, pH 7.4-7.6) marine water (prepared from Cristalsea Marinemix salts) to a density of 20 crabs per tank. The holding room was maintained on a 12-h light/12-h dark cycle (light on 07:00-19:00 h). Animals were fed rabbit pellets (Nutrientes S.A.) every $3 \mathrm{~d}$, and water was changed after feeding. The temperature of both the holding and experimental rooms was maintained within a range of $22^{\circ}-24^{\circ} \mathrm{C}$. Experiments were carried out within the first week after the animals' arrival. Each crab was used in only one experiment.

\section{Training-testing apparatus}

The experimental unit, the actometer, was described in detail elsewhere (Romano et al. 1990). Briefly, it consists of a bowlshaped plastic container where the crab is lodged; an opaque rectangular screen moves horizontally over the animal's head. Screen displacements evoke a crab's running response and, as a consequence, container vibrations which induce electrical signals through a piezoelectric transducer. Signals recorded during a trial were translated into numerical units ranging from 0 to 8000 . The experimental room had 40 actometers, separated from each other by partitions. A computer was used to program trial sequences, trial duration, and intertrial intervals, as well as to monitor experimental events.

\section{Drugs and injection procedure}

2-4 hydroxy ((4- ((2-pyridinilamino) sulphonyl) phenyl) azo) benzoic acid (sulfasalazine) (Sigma) solution was freshly dissolved in 2-methoxyethanol. Fifty $\mu \mathrm{L}$ of vehicle or drug solution was given through the right side of the dorsal cephalothoracicabdominal membrane by means of a syringe fitted with a sleeve to control depth of penetration to $4 \mathrm{~mm}$, thus ensuring that the injected solution was released roughly at the center of the pericardial sac. The total volume of hemolymph was estimated at 5 $\mathrm{mL}$ (30\% of the body weight) (Gleeson and Zubkoff 1977), resulting in an approximate 100-fold dilution of the drug in hemolymph.

\section{Procedure in memory evaluation experiments}

Each trial lasted $9 \mathrm{sec}$ and consisted of two cycles of presentation of the screen over the actometer. Each cycle lasted $2.5 \mathrm{sec}$ with a 2 -sec interval between cycles. The crab's activity was recorded during the entire trial time.

Each experiment lasted $4 \mathrm{~d}$ and included three phases, namely, training session (day 1), exposure session (day 2), and testing session (day 4). Crabs were individually housed during the intersession interval in plastic containers, covered to a depth of $0.5 \mathrm{~cm}$ with marine water and kept inside dimly lighted drawers. The training session consisted of 15 trials with an intertrial interval (ITI) of $171 \mathrm{sec}$. In the exposure session, the animals were exposed for $5 \mathrm{~min}$ to the training context (i.e., container with plain walls) or to a novel context (i.e., container with white-andblack striped walls), both without visual danger stimulus presentation. The testing session consisted of one trial. Both the training and testing sessions were preceded by 15 min of adaptation in the actometer. The actometer used during the training session is referred to as the training context. In all experiments, one crab's group was trained (TR-group) while the other half was located in the actometers but remained untrained (control group, CT-group).

In the pharmacological experiments, a pair of CT-TR group was injected with vehicle (VEH-pair) or sulfasalazine (SSZ-pair) 20 min before the exposure session. Each experiment consisted of four groups ( $n=20-40$ for each group). 


\section{Data analysis and amnestic effect evaluation}

Retention of learning acquired during training was considered when a significantly lower level of response in the testing session was found for a trained group relative to the control group injected with the same solution (drug or vehicle). The rationale of this criterion is that in the previous experiments performed in our laboratory, a significant difference ( $t$-test, $\alpha=0.05$ ) between trained (TR) and untrained groups (CT) was invariably disclosed at testing session $24 \mathrm{~h}$ or more after training when 15 or more training trials $($ ITI $=171 \mathrm{sec})$ were given. Such significant differences were also found when crabs were injected with vehicle at diverse pre- and post-training intervals. Accordingly, predictions are for a significant difference at testing between CT and TR groups. Therefore, throughout this study, results for the behavioral experiments were analyzed with a priori planned comparisons using a weighted means ANOVA with $\alpha$ (per comparison error rate) $=0.05$, according to the standard method (Howell 1987). The lack of differences between CT and TR groups is thus assumed as an amnestic effect. A comparison between control groups injected with drug or vehicle was necessary in order to determine eventual drug side effects affecting the response level at testing in a way not related to training experience. In the first pharmacological experiment, the statistical analysis of testing data included a set of three a priori planned comparisons, namely CT-VEH vs. TR-VEH, CT-SSZ vs. TR-SSZ, and CT-VEH vs. CT-SSZ, using a weighted means ANOVA with $\alpha$ (per comparison error rate) $<0.05$ (Rosenthal and Rosnow 1985; Howell 1987). In the first comparison, a difference between CT-VEH vs. TR-VEH groups was expected due to the reduction in response level induced by training in the latter group. On the contrary, in the second comparison, if the drug produced an amnesic effect, no difference was expected between the CT-SSZ and TR-SSZ groups. Finally, as long as the drug does not affect the level of response at testing, no difference was expected in the comparison between control groups. In the second experiment, all groups were injected with the drug, and planned comparisons were applied to CT vs. TR groups in the Same or Novel context, respectively. In the third pharmacological experiment, we used the same design as that of the first experiment, using two pair of CT-TR groups injected either with vehicle (VEH groups) or with indomethacin $100 \mu \mathrm{M}$.

\section{Electrophoretic mobility shift assay}

Immediately after re-exposure animals were anesthetized by immersion in ice-cold water for $2 \mathrm{~min}$. The central brain (supraesophageal ganglion) was then dissected. Twenty ganglions per sample were pooled in $1 \mathrm{~mL}$ buffered crab saline solution $(\mathrm{pH}$ 7.6). Nuclear extracts were obtained as described (Freudenthal and Romano 2000). To assess NF-kB activity, $12 \mu \mathrm{g}$ of nuclear protein extracts were used and double-stranded oligonucleotide DNA containing the NF- $\mathrm{BB}$ binding site (5'-AGTTGAGGGGACTTTCCCAGGC- ${ }^{\prime}$, binding site in bold) (Promega) was used as probe. With this probe, a single and specific retarded band is found (Freudenthal et al. 1998). The relative optical density (ROD) of the band was estimated using NIH ImageJ $1.29 \times$ software. All measures were made with exposures within the linear range of the film (Agfa CP-BU). Images were digitalized by means of a scanner for negatives (Umax PowerLook III). Protein contents of the extracts were measured in triplicate by the Bradford method and checked for quality and quantity by comparing pattern intensities in SDS-PAGE. CT vs. TR group comparisons were performed by $t$-test.

\section{Acknowledgments}

This work was supported by FONCYT (grant 01-06041) and Fundación Antorchas (grant 14116-79). We thank Alejandro Delorenzi, Maria E. Pedreira, and Liliana Orelli for their assistance.

\section{References}

Albensi, B.C. and Mattson, M.P. 2000. Evidence for the involvement of TNF and NF-кB in hippocampal synaptic plasticity. Synapse 35: $151-159$.
Bahar, A., Dorfman, N., and Dudai, Y. 2004. Amygdalar circuits required for either consolidation or extinction of taste aversion memory are not required for reconsolidation. Eur. J. Neurosci. 19: 1115-1118.

Debiec, J., LeDoux, J.E., and Nader, K. 2002. Cellular and systems reconsolidation in the hippocampus. Neuron 36: 527-538.

DiDonato, J.A., Hayakawa, M., Rothwarf, D.M., Zandi, E., and Karin, M. 1997. A cytokine-responsive IкB kinase that activates the transcription factor NF-кB. Nature 388: 548-554.

Dudai, Y. and Eisenberg, M. 2004. Rites of the passage of the engram: Reconsolidation and the lingering consolidation hypothesis. Neuron 44: $93-100$

Freudenthal, R. and Romano, A. 2000. Participation of Rel/NF-кB transcription factor in long-term memory in the crab Chasmagnathus. Brain Res. 855: 274-281.

Freudenthal, R., Locatelli, F., Hermitte, G., Maldonado, H., Delorenzi, A., and Romano, A. 1998. Kappa-B like DNA binding activity is enhanced after spaced training that induces long-term memory in the crab Chasmagnathus. Neurosci. Let. 242: 143-146.

Freudenthal, R., Romano, A., and Routtenberg, A. 2004. Activation of the transcription factor NF-кB after in vivo perforant path LTP in the mouse hippocampus. Hippocampus 14: 677-683.

Frey, U. and Morris, R.G.M. 1997. Synaptic tagging and long-term potentiation. Nature 385: 533-536.

Gleeson, R.A. and Zubkoff, P.L. 1977. The determination of hemolymph volume in the blue crab, Callinectes sapidus, utilizing

${ }^{14}$ C-thiocyanate. Comp. Biochem. Physiol. 56A: 411-413.

Hermitte, G., Pedreira, M.E., Tomsic, D., and Maldonado, H. 1999. Context shift and protein synthesis inhibition disrupt long-term habituation after spaced, but not massed, training in the crab Chasmagnathus. Neurobiol. Learn. Mem. 71: 34-49.

Hoult, J.R. 1986. Pharmacological and biochemical actions of sulphasalazine. Drugs 32: 18-26.

Howell, D.C. 1987. Statisticals methods of psychology, 2nd ed. Duxbury, Boston.

Kida, S., Josselyn, S.A., Peña Ortiz, S., Kogan, J.H., Chevere, I., Masishige, S., and Silva, A.J. 2002. CREB required for stability of new and reactivated fear memories. Nat. Neurosci. 5: 348-355.

Lee, J.L.C., Everitt, B.J., and Thomas, K.L. 2004. Independent cellular processes for hippocampal memory consolidation and reconsolidation. Science 304: 839-843.

Lozada, M., Romano, A., and Maldonado, H. 1990. Long-term habituation to a danger stimulus in the crab Chasmagnathus. Physiol. Behav. 47: 35-41.

Mactutus, C.F., Riccio, D.C., and Ferek, J.M. 1979. Retrograde amnesia for old (reactivated) memory: Some anomalous characteristics. Science 204: 1319-1320.

Martin, K.C., Casadio, A., Zhu, H., Yaping, E., Rose, J.C., Chen, M., Bailey, C.H., and Kandel, E.R. 1997. Synapse-specific, long-term facilitation of Aplysia sensory to motor synapses: A function for local protein synthesis in memory storage. Cell 91: 927-938.

Meberg, P.J., Kinney, W.R., Valcourt, E.G., and Routtenberg, A. 1996. Gene expression of the transcription factor NF-кB in hippocampus: Regulation by synaptic activity. Mol. Brain. Res. 38: 179-190.

Meffert, M.K., Chang, J.M., Wiltgen, B.J., Fanselow, M.S., and Baltimore, D. 2003. NF-кB functions in synaptic signaling and behavior. Nat. Neurosci. 10: 1072-1078.

Mercurio, F., Zhu, H., Murray, B.W., Shevchenko, A., Bennet, B.L., Li, J., Young, D.B., Barbosa, M., Mann, M., Manning, A., et al. 1997. IKK-1 and IKK-2 -cytokine-activated IкB kinases essential for NF-кB activation. Science 278: 860-866.

Merlo, E., Freudenthal, R., and Romano, A. 2002. The ІкB kinase inhibitor sulfasalazine impairs long-term memory in the crab Chasmagnathus. Neuroscience 112: 161-172.

Misanin, J.R., Miller, R.R., and Lewis, D.J. 1968. Retrograde amnesia produced by electroconvulsive shock following reactivation of a consolidated memory trace. Science 16: 554-555.

Myers, K.M. and Davis, M. 2002. Behavioral and neural analysis of extinction. Neuron 36: 567-584.

Nader, K., Schafe, G.E., and LeDoux, J.E. 2000. Fear memories require protein synthesis in the amygdala for reconsolidation after retrieval. Nature 406: 722-726.

Pedreira, M.E. and Maldonado, H. 2003. Protein synthesis subserves reconsolidation or extinction depending on reminder duration. Neuron 38: 863-869.

Pedreira, M.E., Dimant, B., Tomsic, D., Quesada-Allue, L.A., and Maldonado, H. 1995. Cycloheximide inhibits long-term habituation and context memory in the crab Chasmagnathus. Pharmacol. Biochem. Behav. 52: 385-395.

Pedreira, M.E., Dimant, B., and Maldonado, H. 1996. Inhibitors of protein and RNA synthesis block context memory and long-term habituation in the crab Chasmagnathus. Pharmacol. Biochem. Behav. 54: $611-617$. 
Pedreira, M.E., Pérez-Cuesta, L.M., and Maldonado, H. 2002. Reactivation and reconsolidation of long-term memory in the crab Chasmagnathus: Protein synthesis requirement and mediation by NMDA-type glutamatergic receptors. J. Neurosci. 22: 8305-8311.

Przybyslawski, J., Roullet, P., and Sara, S.J. 1999. Attenuation of emotional and nonemotional memories after their reactivation: Role of $\beta$-adrenergic receptors. J. Neurosci. 19: 6623-6628.

Romano, A., Lozada, M., and Maldonado, H. 1990. Effects of naloxone pretreatment on habituation in the crab Chasmagnathus granulatus. Behav. Neur. Biol. 53: 113-122.

Rosenthal, R. and Rosnow, R.L. 1985. Contrast analysis focused comparisons in the analysis of variance. Cambridge University Press, Cambridge, UK.

Salinska, E., Bourne, R.C., and Rose, S.P.R. 2004. Reminder effects: The molecular cascade following a reminder in young chicks does not recapitulate that following training on a passive avoidance task. Eur. J. Neurosci. 19: 3042-3047.

Sara, S.J. 2000. Retrieval and reconsolidation: Toward a neurobiology of remembering. Learn. Mem. 7: 73-84.

Summers, M.J., Crowe, S.F., and Ng, K.T. 1997. Administration of DL-2-amino-phosphonovaleric acid (AP5) induces transient inhibition of reminder-activated memory retrieval in day-old chicks. Cogn. Brain Res. 5: 311-321.

Taubenfeld, S.M., Milekic, M.H., Monti, B., and Alberini, C.M. 2001. The consolidation of new but not reactivated memory requires hippocampal C/EBP $\beta$. Nat. Neurosci. 8: 769-771.

Tomsic, D., Pedreira, M.E., Romano, A., Hermitte, G., and Maldonado, H. 1998. Context-US association as a determinant of long-term habituation in the crab Chasmagnathus. Anim. Learn. Behav. 26: $196-204$.

Wahl, C., Liptay, S., Adler, G., and Schmid, R. 1998. Sulfasalazine: A potent and specific inhibitor of Nuclear Factor к. B.J. Clin. Invest. 101: $1163-1174$.

Weber, C.K., Liptay, S., Wirth, T., Adler, G., and Schmid, R.M. 2000. Suppression of NF- $\mathrm{\kappa B}$ activity by sulfasalazine is mediated by direct inhibition of ІкB kinases $\alpha$ and $\beta$. Gastroenterology 119: 1209-1218.

Yeh, S.H., Lin, C.H., Lee, C.F., and Gean, P.W. 2002. A requirement of nuclear factor-кB activation in fear-potentiated startle. J. Biol. Chem. 277: 46720-46729.

Yeh, S.H., Lin, C.H., and Gean, P.W. 2004. Acetylation of nuclear factor- $\mathrm{B}$ in rat amygdala improves long-term but not short-term retention of fear memory. Mol. Pharmacol. 65: 1286-1292.

Yin, M.J., Yamamoto, Y., and Gaynor, R.B. 1998. The anti-inflammatory agents aspirin and salicylate inhibit the activity of IкB kinase- $\beta$. Nature 396: 77-80.

Received June 11, 2004; accepted in revised form December 9, 2004. 


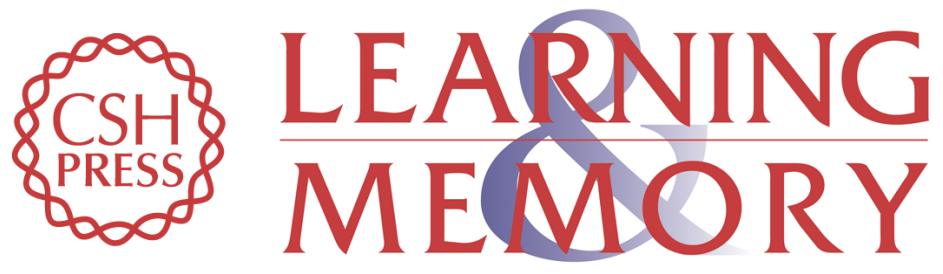

\section{Activation of the transcription factor NF- $\mathrm{KB}$ by retrieval is required for long-term memory reconsolidation}

Emiliano Merlo, Ramiro Freudenthal, Héctor Maldonado, et al.

Learn. Mem. 2005, 12:

Access the most recent version at doi:10.1101//m.82705

References This article cites 36 articles, 8 of which can be accessed free at: http://learnmem.cshlp.org/content/12/1/23.full.html\#ref-list-1

License

Email Alerting Receive free email alerts when new articles cite this article - sign up in the box at the Service top right corner of the article or click here. 